\title{
Terá Cor a Pandemia? 0 impacto da Covid-19 nos Pequenos empreendedores negros ${ }^{1}$
}

\author{
Angélica Kely de Abreu² \\ Giovanni Silva Beviláqua ${ }^{3}$ \\ Marco Aurélio Bedêt \\ Mauro Oddo Nogueira ${ }^{5}$
}

\section{INTRODUÇÃO}

É desnecessário discorrer sobre a gravidade e a profundidade dos impactos socioeconômicos da pandemia da Covid-19 no Brasil, pois esse tema vem povoando tanto a literatura científica quanto a mídia em geral ao longo dos últimos meses. Também é escusado reproduzir aqui os dados já amplamente conhecidos de que tais impactos se mostram muito mais significativos no âmbito dos pequenos negócios, ou ainda as chamadas micro e pequenas empresas (MPEs). ${ }^{6}$ São, portanto, fatos conhecidos e em relaçáo aos quais náo cabe aqui reproduzir o debate. Mas as origens, as causas dessa realidade, a despeito de também já terem sido amplamente apresentadas, merecem ser resgatadas e aprofundadas.

A medida sanitária mais largamente empregada para a contenção da propagação da doença foi, em níveis variados de intensidade, o distanciamento social. Isso implicou a redução ou até mesmo a paralisaçấo total das atividades de grande parte das empresas do país (Sebrae, 2020e), notadamente as de comércio e serviços ditos presenciais e não essenciais - e é exatamente nesses setores que operam a maior parte das MPEs do país. ${ }^{7}$ Contudo, somente essa distinção na composição setorial não é suficiente para explicar a diferença da magnitude do impacto da Covid-19 nas firmas de portes diversos. Em outras palavras, para além do fato de a pandemia ter impactado mais diretamente as MPEs, o fenômeno tornou evidente sua menor resiliência, ou, dito de outra forma, sua maior vulnerabilidade. Essa vulnerabilidade se materializa em inúmeros aspectos, particularmente na baixa capacidade de sobreviver sem faturamento, ${ }^{8}$ na maior dificuldade de acesso a créditos bancários e no menor índice de inclusão digital (Sebrae, 2020b). A isso tudo, soma-se a menor disponibilidade de políticas de apoio governamental específicas para o segmento durante a crise, bem como a inadequação de muitas delas frente à realidade dessas empresas (Nogueira et al. 2020).

$\mathrm{Na}$ realidade, esse conjunto de evidências nada mais é do que o resultado de uma realidade na qual, historicamente, as MPEs e a economia informal ocupam uma posição marginal no debate

1. DOI: http://dx.doi.org/10.38116/bapi26art7

2. Pesquisadora do Programa de Pesquisa para o Desenvolvimento Nacional (PNPD) na Diretoria de Estudos e Políticas Sociais (Disoc) do Ipea.

3. Analista técnico da Unidade de Capitalização e Serviços Financeiros do Sebrae Nacional.

4. Coordenador do Núcleo de Estudos e Pesquisas da Unidade de Gestão Estratégica do Sebrae Nacional.

5. Técnico de planejamento e pesquisa na Diretoria de Estudos e Políticas Setoriais de Inovação e Infraestrutura (Diset) do Ipea.

6. Para classificação por porte das empresas foram utilizados os parâmetros estabelecidos na Lei Geral das MPEs, a Lei Complementar № 123/2006, que instituiu o Simples Nacional.

7. Segundo dados do Serviço Brasileiro de Apoio às Micro e Pequenas Empresas (Sebrae), 85, 1\% das MPEs atuam nesses setores, contra pouco mais da metade das médias e grandes empresas (56,3\%) (Sebrae, 2020a).

8. Grosso modo, é a relação entre o montante do capital de giro da empresa e seu custo fixo diário, que se expressa em números de dias que a empresa é capaz de sobreviver sem faturamento. 
econômico e na concepção das políticas públicas de desenvolvimento econômico. A despeito desse conjunto de empreendimentos ocupar cerca de $75 \%$ dos postos de trabalho no país (Nogueira, Silva e Carvalho, 2020) e representarem 99\% dos empreendimentos formais (Sebrae, 2020a), sua abordagem, seja nos cursos de economia ou administração, seja no âmbito das políticas econômicas, quando presente sempre se deu a partir da perspectiva de uma "questão social" e não de um fato econômico. ${ }^{9}$ Esperado, portanto, que sendo historicamente mais vulneráveis, esses agentes econômicos tenham sigo mais gravemente impactados frente às vicissitudes impostas pela pandemia.

A pergunta que aqui fazemos é se existem aqueles que poderíamos considerar como sendo mais vulneráveis entre os vulneráveis. Nossa hipótese é que há, sim, um grupo de pessoas empreendedoras que, entre os proprietários de MPEs, apresentam características estruturais que tornam ainda mais difícil a superação dos problemas advindos da pandemia no âmbito de seus empreendimentos: os empreendedores negros. Para isso, utilizamos neste estudo um conjunto de dados secundários, estudos e pesquisas recentes disponibilizados por organizaçóes como o Sebrae, Instituto Brasileiro de Geografia e Estatística (IBGE) e/ou pesquisas já tradicionais sobre o tema empreendedorismo, como o Global Entrepreneurship Monitor (GEM), tendo como corte principal de análise a variável cor/raça dos empreendedores brasileiros. A opção pelo uso desses trabalhos se deve ao fato de que o tema ainda foi muito pouco abordado pela Academia, o que, em si só, já é um sinal de pouca atenção da sociedade à questão das desigualdades entre empreendedores de cor raça diferentes em um país como o Brasil.

Para apresentar o estudo, além desta seção introdutória, discutimos de forma sucinta, na seção 2, a questão do discurso do empreendedorismo e da inserção do empreendedor negro nesse contexto. Na seção 3, apresentamos os resultados das pesquisas realizadas junto aos empreendedores durante a pandemia da Covid-19, registrando a maior severidade de seu impacto nos empreendedores negros. Por fim, à guisa de conclusão, na seção 4 discutimos a reprodução da maior vulnerabilidade da população negra também no contexto do empreendedorismo.

\section{LUGAR DO NEGRO NO EMPREENDEDORISMO}

Antes mesmo da pandemia, a condição de desigualdade de cor/raça entre os empreendedores brasileiros já estava documentada em estudos e pesquisas como as do Sebrae e do GEM. Por exemplo, o GEM, que é a principal pesquisa sobre empreendedorismo no mundo, publicou, nos últimos três anos (2017, 2018 e 2019), relatórios específicos por cor/raça no Brasil. O último desses relatórios (IBQP e Sebrae, 2019a), referente ao ano de 2019, mostra, entre outras coisas, que, entre os empreendedores iniciais, a motivação para abrir um negócio "Para ganhar a vida porque os empregos são escassos" chegava a $86,6 \%$ no caso dos empreendedores brancos e a $90 \%$ no caso dos empreendedores negros. Estes últimos ainda apresentavam renda e escolaridade mais baixas, produtos e serviços menos inovadores, métodos/processos mais antigos, menor inserção internacional, negócios menores (menor faturamento e menor número de empregados) e expectativa mais baixa de expansão dos postos de trabalho. Ainda, o relatório de 2018, quando ainda era calculada a taxa de empreendedorismo por oportunidade/necessidade, identificou sistematicamente taxas de criação de negócios "por oportunidade" maiores entre os brancos para todo o período entre 2013 e $2018 .{ }^{10}$ Em 2018, apenas

9. Para mais detalhes sobre essas constatações, ver Nogueira e Zucoloto (2019).

10. Em 2019, essa variável foi substituída pela análise de quatro motivações distintas. 
55,5\% dos empreendedores iniciais negros criou seu negócio "por oportunidade”, contra 71,5\% no caso dos empreendedores brancos.

Por sua vez, Sebrae (2019) mostra que a proporção de empregadores e conta própria com Cadastro Nacional de Pessoa Jurídica (CNPJ) entre brancos era o dobro da verificada entre os negros (40\% e 19\%, respectivamente). O nível de informalidade entre empreendedores negros continuou se mostrando mais alto na média de todas as cinco grandes regióes do país e quando comparados os níveis de escolaridade semelhantes. Por exemplo, entre os empreendedores negros com nível superior, $47 \%$ possuíam CNPJ; entre os brancos, $62 \%$.

O discurso do empreendedorismo foi alavancado ao status de política de trabalho e renda a partir da institucionalização da figura do microempreendedor individual (MEI), instituída pela Lei Complementar no 128/2008, elaborada pelo governo federal para estimular a formalização de trabalhadores autônomos. A criação da figura do MEI proporcionou, sim, uma melhora no processo de formalização de parte dos empreendimentos informais (Corseuil, Nery e Ulyssea, 2014).

De lá para cá, algumas políticas públicas específicas para o empreendedor negro foram implementadas, todas com o condão de oferecer capacitação para esse estrato social. A exemplo, temos o Programa Inova Jovem, da Secretaria Nacional da Juventude (SNJ); o Projeto Brasil Afroempreendedor, demanda da sociedade civil junto ao Sebrae; e o Plano Setorial de Qualificação (Planseq) Afro, parceria entre Ministério do Trabalho e Emprego e a Secretaria Especial de Políticas de Promoção de Igualdade Racial (Seppir), cujo objetivo era qualificar a população negra desempregada oferecendo diversos cursos profissionalizantes.

Esse discurso retraduziu a experiência do trabalhador "chefe de si", tornando-o exemplo de um trabalhador moderno, flexível, dotado da capacidade de se adaptar e de superar as barreiras materiais de sua existência social para desenvolver o seu espírito de "animal empreendedor" (Figueiredo, 2012). O Estado, nesse momento, deixa de ser o regulador das relaçóes trabalhistas e passa a fomentar o homem-indústria.

Assim o "empreendedorismo" ganha proeminência sobre as relaçóes assalariadas, principalmente com a Reforma Trabalhista instituída pela Lei nํㅜ 13.467/2017, que, segundo seus proponentes, possibilitaria incrementar o espaço de liberdade entre trabalhadores e empregados, ampliando o poder de transigir (Silva, 2018). Esse poder, supostamente, teria sido bloqueado por legislaçóes paternalistas, sendo o seu melhor exemplo a Consolidação das Leis do Trabalho (CLT). Também encontrariam bloqueio no corpo protetivo instituído pela Constituição Federal de 1988, cujo art. 7o, incisos IV e VII, vincula o salário à necessidade de atender questóes vitais básicas como a moradia, alimentação, educação, saúde, lazer, transporte, previdência social e vestuário, inviabilizando a inclinação "natural" da ordem econômica à maximização do lucro. Destravar as barreiras institucionais criadas para proteger trabalhadores, mas que supostamente violariam a liberdade individual, é o pretexto último de uma série de reformas que se anunciaram nos últimos anos. Em última instância, preconiza-se que todos esses direitos seriam alcançáveis através de estímulos à livre iniciativa, despertando o ethos empresarial que habita cada sujeito singular. Os direitos seriam, nesse sentido, resultado do mérito dos próprios indivíduos, sendo um desestímulo ao espírito empreendedor os excessos de regulação pública sobre a esfera privada. Também seria possível socializar sujeitos capazes de elaborar trajetórias profissionais bem-sucedidas, eventualmente catapultadas pelas suas próprias desvantagens 
comparativas, se tivéssemos trajetórias formativas dirigidas à construção de uma cidadania escorada em um ethos competitivo e mais próximo da demanda de mercado.

Em resumo, para produzir novos empreendedores, o Estado brasileiro vem promovendo sucessivas transformaçóes nas ofertas públicas de bens e serviços e em sua estrutura regulatória, redefinindo os horizontes da ação estatal e as suas responsabilidades enquanto ente provedor de proteção e garantidor de direitos. O conceito de empreendedorismo passou, portanto, a ser instrumentalizado em políticas públicas como solução ao aumento do desemprego e da exclusão social. Ao empreendedor cabe a inventividade, a adaptaçáo, a resiliência e o risco da atividade econômica. A razáo empreendedora, contudo, mostra-se frágil em um cenário de crise, especialmente quando ele se apresenta com a contundência da atual e em um panorama no qual as políticas públicas de apoio ao segmento vêm se mostrando morosas e insuficientes. Entre aqueles que aderiram a essa lógica de mercado, tais fragilidades tornam-se ainda mais latentes quando lançamos o olhar sobre o empreendedor negro.

\section{OS IMPACTOS DA COVID-19 NOS EMPREENDEDORES NEGROS}

Desde praticamente o início da pandemia no Brasil, o Sebrae Nacional vem conduzindo um survey mensal junto aos MEIs e proprietários de MPEs a fim de dimensionar seus impactos nesse segmento (Sebrae, 2020b). Até agosto de 2020, no âmbito dos sete surveys realizados, foram produzidos relatórios específicos com corte por cor/raça em três ediçóes (quarta, quinta e sétima ediçóes). ${ }^{11}$ Nessas, entre as principais conclusóes, se destacam as relacionadas a seguir.

- Foi maior a proporçáo de empreendedores negros que foi afetada pelas paralisações da economia (restriçôes de circulação, interrupçóes temporárias, quarentena, lockdown etc.). Na quarta edição, por exemplo, $70 \%$ dos empreendedores negros se diziam prejudicados por quarentenas ou lockdwon, contra $60 \%$ no caso dos empreendedores brancos.

- Na quinta edição, uma porcentagem maior de brancos afirmou conhecer e já ter implementado os protocolos de segurança para funcionamento da sua atividade.

- Segundo Sebrae (2020b), o impacto mais forte sobre os empreendedores negros se deu porque sua presença é maior nas periferias das grandes metrópoles, onde a Covid-19 foi mais intensa, e porque é maior a proporção dos negócios que só consegue funcionar presencialmente $(26 \%$ contra $20 \%$ no caso dos brancos, na quarta edição).

- O nível de digitalização dos empreendedores negros era menor, o que colaborou com maiores dificuldades em se ajustarem à queda da demanda: na quarta ediçấo, 57\% dos empreendedores negros já vendia ou passou a vender pelas redes sociais, enquanto no caso dos empreendedores brancos essa porcentagem chegava a $61 \%$.

- Sistematicamente, em todas as ediçóes, os empreendedores negros apareceram com maior proporção de MEI (68\% contra 49\% no caso dos brancos), menor escolaridade (53\% tinham até ensino médio, contra 35\% no caso dos brancos), menor faturamento (44\% faturavam até R \$ $6 \mathrm{mil} / \mathrm{mês,}$ contra $35 \%$ no caso dos brancos), menor quadro de pessoal (62\% não têm funcionários vinculados à Consolidação das Leis do Trabalho - CLT -, contra 49\% no caso dos brancos) e negócios com menos tempo (53\% tinham até cinco anos de atividade, contra $42 \%$ no caso dos brancos). Todos os dados citados aqui são referentes à sétima sondagem.

11. 0 questionário da pesquisa ofereceu como alternativas para cor/raça as opções: amarela, branca, indígena, parda, preta e não sei/não quero informar. Nesses estudos foram comparados os dados dos respondentes que assinalaram a opção branca com os que assinalaram parda ou preta. 
- Na sétima edição, $37 \%$ dos empreendedores negros estavam com dívidas em atraso, contra 30\% no caso dos brancos.

- Até a sétima edição, $50 \%$ dos negros e $51 \%$ dos brancos buscaram empréstimo em bancos, mas só $16 \%$ dos empreendedores negros que pediram empréstimo conseguiram, enquanto, no caso dos brancos, $27 \%$ dos que pediram conseguiram.

$\mathrm{Na}$ sétima edição, a porcentagem de empreendedores negros que continuavam a funcionar utilizando menos ferramentas digitais (66\%) era menor do que a dos brancos (68\%).

O simples fato de empreendedores negros terem maior presença relativa nas periferias das grandes regiôes metropolitanas, onde a pandemia se apresentou inicialmente mais forte, já motiva neles um impacto mais severo. Além disso, há uma maior presença deles em atividades como serviços domésticos (cuidadores, jardineiros etc.), cabelereiros etc., além de ser comum exercerem atividades de natureza manual. Nesses negócios, a presença física do empreendedor no seu local de trabalho é indispensável (IBQP e Sebrae, 2019a).

O menor uso de ferramentas digitais por parte dos negros está associado a diversos fatores, entre os quais se destaca o exercício de atividades de natureza mais manual, negócios mais difíceis de serem "digitalizados". Logo, o fechamento temporário dos seus estabelecimentos foi proporcionalmente mais impactante para esses. Precisamos observar que, durante a pandemia, cresceu muito o uso de informática na sociedade.

Cabe destaque que, entre os empreendedores negros, é maior a proporção de recusas de empréstimos bancários. Entre aqueles que tentaram um empréstimo no banco, na sétima edição da pesquisa, 50\% dos empreendedores negros e 51\% dos brancos buscaram empréstimos em bancos, mas só $16 \%$ dos empreendedores negros que pediram empréstimo conseguiram, enquanto no caso dos brancos, a taxa de sucesso foi de $27 \%$.

Assumindo como verdadeira a premissa de que nada é mais desigual do que tratar desiguais de forma igual, fica evidente que, caso queiram ser bem-sucedidos, em especial nesse momento grave da economia brasileira, os programas de estímulo aos pequenos negócios (e ao empreendedorismo) deveriam considerar a realidade marcada pelas disparidades entre os empreendedores negros e brancos, para o aumento da eficiência de suas açôes.

\section{CONSIDERAÇÕES FINAIS}

O objetivo deste trabalho foi problematizar a política empreendedora, tão difundida pelo Estado nos últimos anos, e tentar evidenciar a vulnerabilidade do negro empreendedor a partir da análise do maior impacto sofrido, na pandemia, por esse estrato social. E, nesse sentido, alertar para o fato de que a transformação desse discurso, apresentado muitas vezes como panaceia para a superação de desigualdades, em políticas públicas que não levem em conta desigualdades "de origem", pode acabar por retroalimentar e aprofundar essas mesmas desigualdades.

A compreensão da posição do negro no mercado de trabalho permite identificar questóes estruturais e desigualdades nos processos produtivos e reprodutivos que vão, com o passar do tempo, explicando com cada vez mais força a subalternizaçáo dos segmentos identificados por sua cor/raça e, por conseguinte, sua posição social (Almeida, 2018). As desigualdades, por assim dizer, são o 
desaguadouro da combinação complexa de desvantagens materiais e de uma hegemonia estrutural branca que afeta as capacidades pessoais e a autoconfiança de grupos sociais estigmatizados.

Limitar o seu campo de atuação a certos lugares sociais é uma forma mais ou menos consciente de evitar frustraçóes, adequando seus desejos e projetos pessoais às condiçóes objetivas que lhe são dadas. Esta pode parecer a única estratégia acessível num contexto em que o baixo nível de mobilização política dos segmentos negros inviabiliza a construção de estratégias solidárias, coletivas e autônomas de organização dos grupos dominados. Embora esta desmobilização também desincumba os grupos dominantes de uma organização reativa, ela oferece a amálgama necessária para a consolidação de uma ideologia racial harmoniosa, capaz de disfarçar as práticas discriminatórias e fazer da aceitação pragmática da ordem racial um meio de minimizar os sofrimentos que a cor da pele propicia. Isso implica dizer que o modelo de discriminaçáo racial brasileiro tem sua eficácia máxima medida pelo bloqueio da mobilização coletiva do grupo subordinado, tornando improvável e excepcional a mobilidade ascendente dos indivíduos.

A citação de exemplos de sucesso, nesse aspecto, funciona como artefatos individualizantes da experiência social, fascinantes numa sociedade suposta e declaradamente meritocrática, mas produtora de frustraçóes em escala alargada. Conduzindo as escolhas individuais à condição de fator determinante a uma trajetória ascensional, esses exemplos concorrem para a despolitização da experiência nas relaçóes de trabalho e o ocultamento das estruturas de poder que as informam. Dito de outro modo, trata-se de uma forma mais ou menos sofisticada de reforçar a democracia racial, dificultando a possibilidade de desenvolvimento de estratégias solidárias coordenadas entre pessoas que não se identificam enquanto grupo. No entanto, as discriminaçóes operam cotidianamente como uma pletora de açóes individuais e não coordenadas, com resultados de curto alcance, cujos efeitos agregados tornam altamente resilientes a estrutura das desigualdades ancoradas no elemento racial. Cabe chamar a atenção para o fato de que, no âmbito dos empreendedores negros, há um grupo ainda mais vulnerável: o das mulheres empreendedoras negras. Acreditamos que este seja também merecedor de um olhar mais acurado, seja por parte dos pesquisadores, seja dos formuladores de política públicas. $^{12}$

Essa realidade se mostra de forma mais ou menos sutil e em maior ou menor grau em diversos aspectos da sociedade brasileira nos quais as possibilidades de ascensão social e sucesso econômico e profissional são apresentadas como possibilidades universalizadas, dependentes do mérito individual. Mais ainda no discurso do empreendedorismo lastreado no senso comum, para o qual o sucesso é resultado apenas das capacidades e habilidades individuais de competir no mercado regulado táo somente pelar "leis da seleção natural". A situação de crise que o país atravessa por conta da pandemia da Covid-19 já evidencia claros indícios de que o mundo real não é bem assim. 


\section{REFERÊNCIAS}

ALMEIDA. S. L. de. O que é racismo estrutural? Belo Horizonte (MG): Letramento, 2018.

CORSEUIL, C. H. L.; NERI, M. C.; ULYSSEA, G. Uma análise exploratória dos efeitos da política de formalizaçáo dos microempreendedores individuais. Brasília: Ipea, 2014. (Texto para Discussão, n. 1939).

FIGUEIREDO. A. Classe média negra: trajetórias e perfis. Salvador: Edufba, 2012.

IBQP - INSTITUTO BRASILEIRO DE QUALIDADE E PRODUTIVIDADE; SEBRAE - SERVIÇO BRASILEIRO DE APOIO ÀS MICRO E PEQUENAS EMPRESAS. Global Entrepreneurship Monitor (GEM): Empreendedorismo no Brasil - 2019, recorte temático: Cor/Raça. Brasília IBQP/ Sebrae, 2019a. Disponível em: <https://is.gd/AzzoyR>. Acesso em: 31 ago. 2020.

Global Entrepreneurship Monitor (GEM): Empreendedorismo no Brasil - 2019, recorte temático: Sexo. Brasília: IBQP/Sebrae, 2019b. Disponível em: <https://is.gd/42sF2p >. Acesso em: 31 ago. 2020.

NOGUEIRA, M. O.; SILVA, S. P.; CARVALHO, S. S. Socorro governamental às pequenas unidades produtivas frente à atual pandemia. Brasília: Ipea, 2020. (Nota Técnica, n. 63).

NOGUEIRA, M. O.; ZUCOLOTO, G. F. Um pirilampo no poráo: um pouco de luz nos dilemas da produtividade das empresas e da informalidade no Brasil. Brasília: Ipea, 2019.

NOGUEIRA, M. O. et al. SOS Covid-19: vacinação em massa para as micro e pequenas empresas. Niterói: Itapuca; Cocuyo, 2020.

SEBRAE - SERVIÇO BRASILEIRO DE APOIO ÀS MICRO E PEQUENAS EMPRESAS. Estudo sobre o empreendedorismo informal no Brasil - 2018. Relatório Especial Brasília: Sebrae, 2019. Disponível em: <https://is.gd/WU1WbM>. Acesso em: 02 out. 2020.

. Painel de Empresas. DataSebrae. Brasília: Sebrae, 2020a. Disponível em: <https://is.gd/ ty5A8o>. Acesso em: 20 ago. 2020.

. O impacto da pandemia de coronavírus nos pequenos negócios. Brasília: Sebrae, 2020b.

Disponível em: <https://is.gd/ArqqbL>. Acesso em: 02 out. 2020.

Observatório global: impacto da Covid-19 nas mulheres. Boletim, n. 21, 5 ago. 2020c.

. Observatório global: empreendedorismo feminino no mundo. Boletim, n. 22, 18 ago. 2020d.

. Observatório global: evolução da Covid-19 até agosto/20. Boletim, n. 23, 18 ago. 2020e.

SILVA, S. P. A estratégia argumentativa da reforma trabalhista no Brasil à luz de dados internacionais.

Boletim Mercado de Trabalho, n. 64, p. 99-110, abr. 2018. 
